\title{
The Dark Triad of personality in psychology students and eco-friendly behavior
}

\author{
Inna Budanova ${ }^{1, *}$ \\ ${ }^{1}$ Don state technical university, Rostov-on-Don 344000, Russia
}

\begin{abstract}
Machiavellianism, narcissism, and non-clinical psychopathy are part of the dark triad and have recently been studied by scientists around the world. Psychologists, as representatives of helping professions, must have a pro-social personality orientation. It is known that the manifestation of individual personality traits occurs maximally in adolescence and early adulthood. Therefore, it is important to assess how the formation of not only professional, but also personal qualities of psychology students takes place. An empirical study examined the manifestation of the dark triad personality traits in psychology students enrolled in different courses of study. It was found that first-year students have a lower level of Machiavellianism than third-year students. Also, statistically significant differences were found in the manifestations of Machiavellianism in men and women. In the group of men, Machiavellianism manifested itself at a higher level than among women. The higher level of Machiavellianism among third-year students of psychology in comparison with first-year students probably reflects their mastery in the learning process of both theoretical and practical foundations of interaction, interpersonal communication, as well as the formation of practical communication skills.
\end{abstract}

\section{Introduction}

The study of negative personality traits in modern science is gaining popularity. The concept of the Dark Triad has become one of the established psychological terms relatively recently. Paulhus, Delroy \& Williams, Kevin found that narcissism, Machiavellianism and non-clinical psychopathy correlate among themselves, and called the combination of these traits in personality the Dark Triad of Personality $[1,2,3]$. The phenomenon of the Dark Triad includes three psychological features - non-clinical narcissism, Machiavellianism and non-clinical psychopathy, each of which is an independent construct that is not reduced to the other two.

The characteristics of narcissism include the lack of empathy and complete disinterest in the problems of others, confidence in superiority over others and the constant struggle to be in the spotlight, low self-control, ill-will, hostility and even aggressiveness when confronted with disagreement and criticism [4].

Machiavellianism in psychology is understood as a combination of at least three components: manipulative techniques in the process of interpersonal interaction, cynical

\footnotetext{
*Corresponding author: buinna@mail.ru
} 
attitude towards other people, ignoring social morality when it prevents it from achieving the desired result [5].

Non-clinical psychopathy is characterized by the ability to make a good impression in superficial acquaintance (external charm), fearlessness, low anxiety, optional, dishonesty, craftiness, lack of regret and remorse, a tendency to antisocial behavior, an inability to learn from one's own mistakes, pathological egocentrism, poverty of the emotional sphere [5].

Students often participate in psychological, psychophysiological, psychogenetic research. [6-10]. Empirical studies from different countries have studied the relationship between the indicators of the Dark Triad and different professions studied by students. Comparing students of different humanitarian areas, namely students of psychology, economics, law and political science, it is known that psychology students had the lowest level of indicators of the dark triad [11]. In a study by Aslı, Doç \& Göncü Köse, the results showed that the scores of Machiavellianism among students of economics, business, and engineering were significantly higher than those of psychology students. [12]. At the same time, comparing students of humanitarian and technical specialties, there is evidence that humanities students have a higher level of Machiavellianism than students of technical specialties. Perhaps this is a consequence of the fact that the content of their education implies the study of the psychological mechanisms of human behavior and methods of managing social systems [13].

Testing the professional interests of high school students with the Slovak study Čopková revealed that high rates of non-clinical psychopathy were shown by students oriented towards the production sphere, compared with students oriented towards art, science and education. Also, in psychopathy, business-oriented students scored higher than arts and education students. At the same time, Machiavellianism, in this study, is the most important feature of the Dark Triad in all professional spheres. [14].

When choosing a profession, it is important to take into account the role of the individual, since the profession affects not only individuals, but also society as a whole. The profession of a psychologist, as well as a teacher, assumes a pro-social orientation and poses certain requirements for personal and professional qualities, the severity of which becomes the key to future professional success $[15,16]$. Thus, it is important for future psychologists to have such personal qualities as sympathy, tolerance, emotional responsiveness, altruism.

Since the number of certified psychologists is increasing every year, and there is no special selection according to the severity of professionally important qualities when entering universities for training in psychological specialties, it is possible that people with a set of personal qualities that are significantly different from the professionally desirable ones may appear among students. This is facilitated by an increase in the number of psychology students in higher educational institutions, and an increasing interest in the study of human psychology, and the popularization of the profession in society as a whole. However, as some studies show, it is not uncommon for those who work in the field of assistance to have features of the Dark Triad [17-20].

The authors explain this by the fact that even a person who decides to help others may have a desire to abuse the power over clients that he has acquired in his profession.

Since personality traits are maximally manifested in adolescence and early adulthood, and at the same time are hardly noticeable in childhood and adolescence, the conditioning of the manifestation of the Dark Triad traits becomes important.

Egorova M.S., Sitnikova M.A. and others studied the phenomenon of the Dark Triad and its relationship with various indicators. Evaluating the relationship of the components of the Dark Triad with age, it is known that a negative correlation between age and the Dark Triad was observed in samples of a wide age range of 18-65 years. [21].

Sex differences in terms of the Dark Triad indicators, regardless of diagnostic methods, show that higher rates of Machiavellianism and non-clinical psychopathy are observed in 
men. [21]. Jonason Peter also writes about decreasing Dark Triad trait scores and increasing their consistency throughout life [22].

The aim of the study was to study the Dark Triad of personality among students of the Faculty of Psychology at different stages of education.

The work suggested that the formation of professional skills, the beginning of a career and an independent life can be a factor contributing to the manifestation of new personality traits, including the traits of the Dark Triad.

\section{Participants and research methods}

On the basis of the faculty "Psychology, Pedagogy and Defectology" of the Don State Technical University in Rostov-on-Don, a study was conducted of the severity of the Dark Triad indicators among undergraduate students. The study involved 140 respondents. Of these, students of the 1 st course of study - 76 and 3rd course of study - 64 people, 100 women and 40 men. All respondents participated in the study voluntarily and were informed that the data obtained in the study will only be used for scientific purposes.

The study was conducted between September and December 2020 using paper and electronic testing. Assessment of severity indicators Dark Triad performed using diagnostic method personality traits questionnaire "Dark Dozen" [23]. Respondents were asked to express different degrees of agreement or disagreement with 12 statements. Statistical processing of data was carried out using the computer program STATISTICA 64. The results obtained were evaluated for compliance with the normal distribution. The application of the Kolmogorov-Smirnov test showed that the studied sample did not correspond to the normal distribution $(\mathrm{p}<0.05)$. Therefore, further analysis of the data was carried out using the nonparametric statistical tests of Spearman and Kruskell-Wallis.

\section{Analysis and results}

Table 1 presents the descriptive characteristics of the level of the Dark Triad by group.

Table 1. Descriptive characteristics of the level of the Dark Triad.

\begin{tabular}{|l|c|c|c|}
\hline \multicolumn{1}{|c|}{ Variables } & $\begin{array}{c}\text { Narcissism } \\
\text { M(SD) }\end{array}$ & $\begin{array}{c}\text { Psychopathy } \\
\text { M(SD) }\end{array}$ & $\begin{array}{c}\text { Machiavellianism } \\
\text { M(SD) }\end{array}$ \\
\hline Total by sample & $12.67(3.51)$ & $7.36(3.32)$ & $10.39(4.06)$ \\
\hline First year students & $12.19(3.31)$ & $7.20(3.30)$ & $9.68(4.09)$ \\
\hline Third year students & $13.25(3.69)$ & $7.55(3.37)$ & $11.25(3.89)$ \\
\hline Men & $13.09(5.39)$ & $9.09(4.28)$ & $14.00(3.29)$ \\
\hline Women & $12.64(3.33)$ & $7.21(3.21)$ & $10.08(3.98)$ \\
\hline
\end{tabular}

Notes: $\mathrm{M}=$ Mean; $\mathrm{SD}=$ Standard deviation.

Analyzing the data in Table 1 shows that mean values Machiavellianism among first-year students are lower than among third-year students. Also the mean values of Machiavellianism in men are higher than in women.

Application of the Kruskell-Wallis test showed that these differences are statistically significant. The connection between Machiavellianism and the respondents' course of study is $\mathrm{H}=6.22$ at the level of significance $\mathrm{p}=0.01$. Indicators of narcissism and psychopathy are not statistically significantly associated with course of study. Evaluating the median values, it is shown that among the third-year students, the median values of the Dark Triad indicator of Machiavellianism are higher than among the group of first-year respondents.

To determine the relationship between Dark Triad traits, correlations (Spearman r) were calculated between Machiavellianism, narcissism and psychopathy. The indicators of the 
Dark Triad generally correlate with each other at the $p<0.05$ significance level. The correlation between narcissism and psychopathy was $\mathrm{R}=0.20$; between narcissism and Machiavellianism $\mathrm{R}=0.44$ and between psychopathy and Machiavellianism $\mathrm{R}=0.46$.

When evaluating the differences by sex, a statistically significant difference $(H=8.89, \mathrm{p}$ $=0.01$ ) was found only in the level of Machiavellianism too. Among the group of male respondents, the median values of the level of Machiavellianism are higher than in the group of women (see Fig. 1).

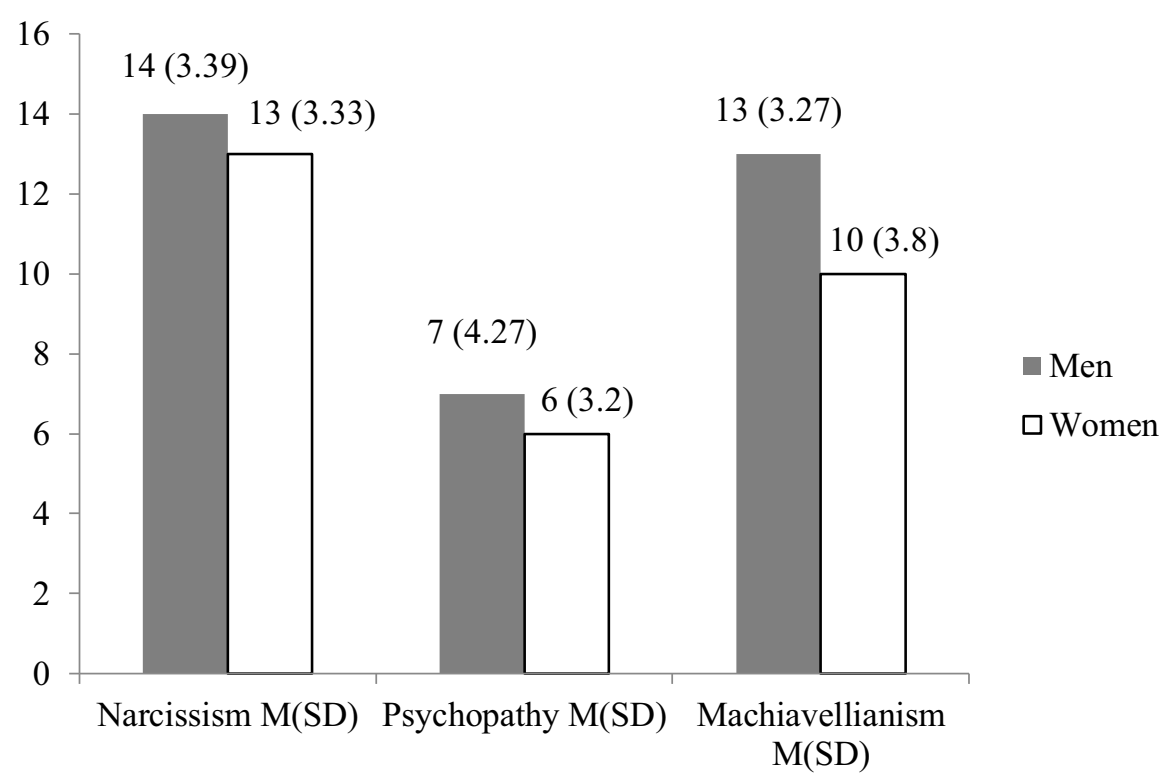

Fig. 1. Median values of narcissism, psychopathy and Machiavellianism in men and women. Notes: $\mathrm{M}=$ Mean; $\mathrm{SD}=$ Standard deviation.

As seen in Fig. 1, the median values of narcissism and psychopathy in the group of male respondents are slightly higher than in the group of women, but these differences are not statistically significant $(\mathrm{p}>0.05)$.

\section{Discussion}

Until recently, both in the choice of profession and in research in general, there was a tendency to concentrate primarily on the so-called bright side of the personality. We are currently seeing an increase in the popularity of studying the concept of the Dark Triad. However, these qualities cannot be unequivocally called negative. Obviously, people exhibiting Dark Triad traits are more likely to look for professions in which they can more easily demonstrate their strength. Success in certain types of professions definitely depends on the presence of such qualities as determination, insensitivity and work for the result. These include law, economics, sports, business and politics.

As a psychologist, as a person working in the field of helping people, it is desirable to have pro-social personality traits. However, future students do not always correspond to this fact when choosing a profession. It is important to assess how studying at a university may be reflected not only in the formation of professional skills, but also in personal traits.

Thus, as a result of the conducted empirical research, the following conclusions were formulated: 
1. Among students-psychologists of the 3rd year of undergraduate studies, the level of Machiavellianism is higher than among the group of students-psychologists of the first year. Perhaps the reason is that first-year students have recently graduated and have not yet adapted to the new conditions of study. It is possible that first-year students have a team spirit, like former schoolchildren, and senior students are already accustomed to learning and achieving their goals on their own and do not associate themselves with the team. It is noted that people brought up in a collectivist culture, in comparison with people brought up in a culture of individualism, tend to define themselves as part of a group and give priority to intragroup goals, pay more attention to context than content. [24].

2. Differences between the groups of men and women manifested itself as a higher level of Machiavellianism in the group of men than among women. The result obtained agrees with the data of other authors [25]. This may be evidence that men are more typical of behavior characterized by the desire to achieve their goals at any cost, including manipulativeness and cynicism towards others.

Thus, in the course of the analysis of the results obtained, the hypothesis about the different degrees of severity of the indicators of the Dark Triad in groups of students of different courses was confirmed. It was found that senior students are more likely to have Machiavellianism than younger students.

The higher level of Machiavellianism among third-year psychology students in comparison with first-year students may also reflects their mastering in the course of training both the theoretical and practical foundations of interaction, interpersonal communication and also the formation of practical communication skills.

If the level of Machiavellianism rises with study at the university and at the same time decreases at large time intervals in middle age, it becomes important to identify the predictors that contribute to the emergence of Machiavellianism.

It is interesting to assess the relationship between the traits of the Dark Triad with emotional intelligence, the value system and a general level of life satisfaction of psychology students at different stages of education.

Understanding the mechanisms of the formation of negative traits at a student age is an important condition for the choice of methods and techniques for teaching and assessing students.

\section{References}

1. D. Paulhus, K. Williams, Journal of Research in Personality 36, 556-563 (2002) 10.1016/S0092-6566 (02)00505-6

2. P. Jonason, J. Foster, A. Oshio et al., Personality and Individual Differences 113, 120124 (2017) 10.1016/j.paid.2017.02.053

3. P. Jonason, A. Oshio, T. Shimotsukasa et al., Personality and Individual Differences 120, 102-106 (2018) 10.1016/j.paid.2017.08.030

4. M.S. Egorova, The Dark Triad In Adult Sibling Dyads, 138-145 (2019) 10.15405/epsbs.2019.07.18

5. M.S. Egorova, O. Parshikova, M. Sitnikova, Personality and Individual Differences 101, 475-476 (2016) 10.1016/j.paid.2016.05.126

6. E.V. Vorobyeva, The technology of an objective psychophysiological assessment of the motivational functions of psychology students (Moscow, 2016) https://elibrary.ru/item.asp?id=27485610

7. E.V. Vorobyeva, P.N. Ermakov, O.S. Saakyan, Psychology in Russia: State of the Art 8(1), 32-42 (2015) 10.11621/pir.2015.0104 
8. V.V. Kosonogov, E.V. Vorobyeva, E.M. Kovsh, P.N. Ermakov, International Journal of Cognitive Research in Science, Engineering and Education 7, 137-142 (2019) 10.5937/IJCRSEE1901137K

9. G. Kozhukhar, A. Belousova, E. Breus, E3S Web Conf. Innovative Technologies in Science and Education (ITSE-2020) 210 (2020) 10.1051/e3sconf/202021018009

10. A. Belousova, E. Belousova, International Journal of Cognitive Research in Science, Engineering and Education 8(2), 27-34 (2020) 10.5937/IJCRSEE2002027B

11. A. Vedel, D. Thomsen, Personality and Individual Differences 116, 86-91 (2017) 10.1016/j.paid.2017.04.030.

12. D. Aslı, K. Göncü Ü. Asli, F. Çankaya, B.P. Fen-Edebiyat, Kalem Uluslararasi Egitim ve Insan Bilimleri Dergisi. 10, 465-484 (2021)

13. S.V. Bykov, Bulletin of the Samara Humanitarian Academy. Series: Psychology 1(17) (2015)

14. R. Čopková, A. Jendrejáková, Social Education 8, 44 - 58 (2020) 10.7441/soced.2020.08.02.03

15. A. Belousova, G. Kozhukhar, INTED 2018 Proceedings. 12th International Technology, Education and Development Conference, 0291-0298 (2018) 0.21125/inted.2018

16. V.I. Pishchik, International Journal of Cognitive Research in Science, Engineering and Education 8, 69-81 (2020) 10.5937/IJCRSEE2002069P

17. P. Babiak, Applied Psychology 44(2), 171-188 (1995) 10.1111/j.14640597.1995.tb01073.x

18. B. Bakir, M. Ozer, M. Uçar et al., Psychological Reports 92(3), 1169-1175 (2003) 10.2466/pr0.2003.92.3c.1169

19. V. Bucknall, S. Burwaiss, D. MacDonald et al., Pathologic Personality Traits in Health Care 187(18), 1359-1363 (2015) 10.1503/cmaj.151135

20. J. Pegrum, O. Pearce, The Bulletin of the Royal College of Surgeons of England 97(8), 331-334 (2015) 10.1308/rcsbull.2015.331

21. M.S. Egorova, M.A. Sitnikova, O.V. Parshikova, Yu.D. Chertkova, Psikhologicheskie Issledovaniya 8(43), 4 (2015) http://psystudy.ru/index.php/eng/2015v8n43e/1196-egorsit43e .html

22. P.K. Jonason, Psikhologicheskie Issledovaniya 8(43), $3 \quad$ (2015) http://psystudy.ru/index.php/eng/2015v8n43e/1195-jonason43e.html

23. T.V. Kornilova, S.A. Kornilov, M.A. Chumakova, M.S. Talmach, Psychological journal 36(2), 99-112 (2015)

24. H. Triandis, Journal of personality 69, 907-24 (2002) 10.1111/1467-6494.696169.

25. M.S. Egorova, Dark Triad As A Predictor Of Bullying In High School Students, 222228 (2018) 10.15405/epsbs.2018.11.02.24 